\title{
Chromatin Folding From Linear Chromosomes to the 4D Nucleus
}

\author{
T. Cheutin, F. Bantignies, B. Leblanc, and G. Cavalli \\ Institut de Génétique Humaine CNRS UPR1142, 34396 Montpellier CEDEX 5, France \\ Correspondence: giacomo.cavalli@igh.cnrs.fr and frederic.bantignies@igh.cnrs.fr
}

\begin{abstract}
The organization of chromatin within the nucleus influences gene expression during cell differentiation and development. Recent work took advantage of the genome-wide localization of molecular marks on chromosomes to analyze their linear distributions at different length scales. Moreover, chromosome conformation capture techniques detect spatial proximity inside the cell nucleus and allow us to characterize local and long-range chromatin loops as well as interchromosomal contacts. These techniques have improved our understanding of chromatin composition in eukaryotic chromosomes, but the principles governing nuclear organization are still little understood. On the one hand, proteins might localize in stable nuclear structures, such as transcription factories, on which chromatin would have to be targeted to be processed. On the other hand, proteins binding to chromatin might induce the formation of specialized nuclear compartments de novo. Current work is aimed at distinguishing between these possibilities and at elaborating predictive models of chromatin folding.
\end{abstract}

Chromatin bears genetic information, forms chromosomes during mitosis, and localizes within the cell nucleus during interphase, adopting two morphologically distinct domains. Heterochromatin is more condensed and usually located at the nuclear envelope and around nucleoli, whereas euchromatin is less condensed and found in the nuclear interior. Although morphologically invisible during interphase, fluorescent in situ hybridization experiments using chromosome-specific DNA libraries demonstrate that each interphase chromosome occupies a distinct territory inside the cell nucleus (Cremer et al. 1993; Foster et al. 2005). Importantly, the human gene-dense chromosome 19 adopts a more internal position in the nucleus than the gene-poor chromosome 18 , showing that chromosome territories are not randomly positioned inside the cell nucleus (Croft et al. 1999). Moreover, the correlation between gene density and the radial arrangement of chromosome territories is conserved during higher-primate genome evolution (Tanabe et al. 2002b). Such radial positioning is not limited to chromosomes territories: The radial localization of individual genes also strongly correlates with gene density and expression, because most transcribed genes are located in the nuclear interior (Foster and Bridger 2005; Kosak et al. 2007). This conventional pattern - in which heterochromatin and repressed genes mainly localize close to the nuclear periphery, whereas the inner part of the nucleus essentially contains euchromatin and expressed genes - is conserved in evolution from unicellular to multicellular organisms (Postberg et al. 2005). During Caenorhabditis elegans development, repressed genes associate with the nuclear envelope of differentiated cells, whereas activation of tissue-specific promoters induces shifts to the nuclear interior in a dominant fashion over silent promoters (Meister et al. 2010). Surprisingly, the nuclear organization appears more flexible than expected, because the rods of nocturnal retinas have an inverted pattern whereby heterochromatin localizes in the nuclear center and euchromatin at the nuclear periphery (Solovei et al. 2009). This study emphasizes the difficulties in functionally interpreting the organization of the cell nucleus, because completely different organizations are not incompatible with viability and specification of the same cell types, although they may result in differences in cell physiology. Noticeably, this inverted pattern was only reported in terminally differentiated cells, and one may argue that the early differentiating cells would require the conventional radial pattern, in agreement with the fact that, in diurnal mammalians, a selective pressure operates toward the conventional radial pattern (Solovei et al. 2009).

Although it has been clearly demonstrated that the cell nucleus is a highly organized structure, the mechanisms responsible for the nonrandom localization of nuclear components remain largely unknown. The cell nucleus appears to be a plastic, complex network of nucleic acid and proteins that form dynamic higher-order structures resulting from both specific and nonspecific forces. The complexity of the networks involved in nuclear organization precludes easy interpretation of the role of any individual element, because its perturbation usually affects the entire network and produces global effects. Another factor that makes nuclear organization difficult to interpret is the low resolution of optical microscopy, which limits the description of the cell nucleus to higher-order structures. To address questions at the molecular level, major technical advances such as chromosome conformation capture (3C), which monitors the molecular contacts between chromatin fibers, are currently used to systematically investigate the average behavior of chromosomes from populations of fixed cell nuclei. Since its introduction (Dekker et al. 2002), 3C and its derivatives have demonstrated that chromatin adopts some 
configurations that are more prevalent than others, involving specific interactions at relatively short distances as well as intra- and interchromosomal long-range contacts. These approaches clearly demonstrate that the chromatin fiber does not randomly fold at the molecular scale, consistent with the nonrandom localization of nuclear compartments described by microscopy. However, the mechanisms organizing the cell nucleus are still poorly understood, and different models have been proposed to explain the nonrandom localization of nuclear structures and chromatin loci. Because the cell nucleus is a dynamic structure, the principles of nuclear organization might rely on selfassembly of nuclear components, which, in turn, depends on their concentration and dynamics. Alternatively, some stable, preassembled nuclear landmark structures (nuclear bodies) may dictate the positioning and dynamics of individual components and organize them in space and time. Mathematical modeling and computer simulations can be used to try to distinguish between these possibilities and address the role of specific and nonspecific forces in nuclear organization and chromatin folding.

\section{THE DIFFERENT LAYERS OF CHROMOSOME FOLDING}

\section{Genome Regulation via Local Chromatin Loops}

To monitor local chromatin arrangements at the molecular level, initial studies focused on regulatory elements that act at a distance from their target genes, such as genetically characterized enhancers or repressive elements (Banerji et al. 1981; Maeda and Karch 2006). The recent use of 3C-based methodologies has revealed a large set of interactions between regulatory elements and their target genes, thus forming higher-order structures (Fig. 1). Therefore, regulatory elements can be closer to their target genes than to intervening sequence, and transcriptional regulation should no longer be considered as a linear process.

The first use of $3 \mathrm{C}$ in mammalian cells was to investigate promoter-enhancer communication at the $\beta$-globin locus (Tolhuis et al. 2002). This study revealed that hypersensitive sites of the locus control region (LCR), located $40-60 \mathrm{~kb}$ away from the active $\beta$-globin genes, come into close spatial proximity with these genes, whereas intervening chromatin with inactive globin genes loops out, creating a structure called the active chromatin hub $(\mathrm{ACH})$. This looped conformation was specific to erythroid cells, where the genes are highly expressed, suggesting that clustering of regulatory elements may facilitate transcriptional activity. Notably, the most distal hypersensitive sites of the $\beta$-globin locus contact each other in erythroid progenitors prior to gene activation (Palstra et al. 2003), and interactions at the $\beta$-globin locus are not disrupted by inhibition of RNA polymerase II (Mitchell and Fraser 2008; Palstra et al. 2008), indicating that loop formation is not simply a consequence of transcription. A high-resolution profile of the topology of the $400-\mathrm{kb}$ genomic region spanning the human $\beta$-globin locus confirmed the ACH structure and revealed a sharp loss of interactions with surrounding genomic sequences, suggesting that this looped conformation might serve to isolate coregulated genes from the flanking genomic environment (Dostie et al. 2006). Since these studies, other looped conformations have been reported for other loci, which often involve protein factor-binding sites and can serve as poised conformations for epigenetic regulation during cell differentiation (for an extensive review, see Sexton et al. 2009). Interestingly, many of these chromatin structures involve the insulator protein CTCF (for review, see Phillips and Corces 2009), and recently, it was found that cohesins are necessary to maintain CTCF-dependent intrachromosomal interactions at specific loci (Hadjur et al. 2009; Nativio et al. 2009; Hou et al. 2010). Therefore, cohesin proteins, which maintain the pairing of sister chromatids, may also maintain the pairing of regulatory elements in chromatin loops.

A recent study has put this model of chromatin loops in a genome-wide perspective (Fullwood et al. 2009). In estrogen-treated cells, ChIP profiles of chromatin bound by the estrogen receptor $\alpha$ (ER- $\alpha$ ), together with a wholegenome interactome analysis of these binding sites using chromatin interaction analysis by paired-end tag sequencing (ChIA-PET), were mapped simultaneously. Multiple interactions between distal- and proximal-to-promoter ER- $\alpha$ sites were found, and the strongest ER- $\alpha$-binding sites are more likely to be involved. Some interactions include multiple genes, indicative of topologically complex structures as described above, whereas others include only single genes, indicative of simpler loop structures. The investigators proposed that the more complex organizations may be partitioned into hubs of core associations between "anchor genes," with more distal interactions made with peripheral "loop genes." Most importantly, a good correlation was observed between chromatin interactions and transcriptional activation, with anchor genes being the most activated following estrogen induction, whereas loop genes and genes not associated with interactions are less strongly up-regulated. One can speculate that these genecentric interaction structures may help to achieve and maintain high local concentrations of transcription components for efficient transcriptional activity.

Chromatin looping and higher-order structure also appear important for transcriptional repression. In the case of Polycomb group ( $\mathrm{PcG}$ )-mediated silencing, the genomic position of PcG targeting elements named Polycomb response elements (PREs) relative to their cognate genes is variable, sometimes positioned within promoters, sometimes positioned at large distances (Schuettengruber et al. 2009). Contact between PREs and promoters by looping was first demonstrated by the tethering of Dam methyltransferase to the Drosophila Fab-7 PRE (Cleard et al. 2006), and another study suggested that PRE may bring PcG proteins to the promoter for silencing (Comet et al. 2006). $3 \mathrm{C}$ and FISH have been subsequently used to investigate the physical and spatial interactions between regulatory regions of the Hox multigenic bithorax complex (BX-C) (Lanzuolo et al. 2007). The BX-C is a 340$\mathrm{kb}$ genomic region that forms a large histone $\mathrm{H} 3$ lysine 27 trimethylated (H3K27me3) repressive domain where PcG proteins are bound at specific regions, including PREs, 
A

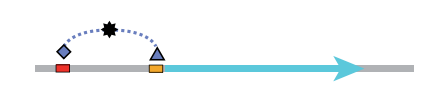

B

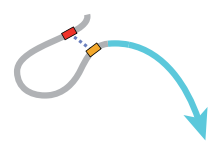

C

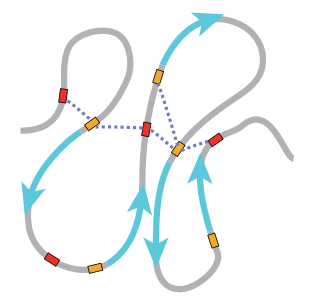

D
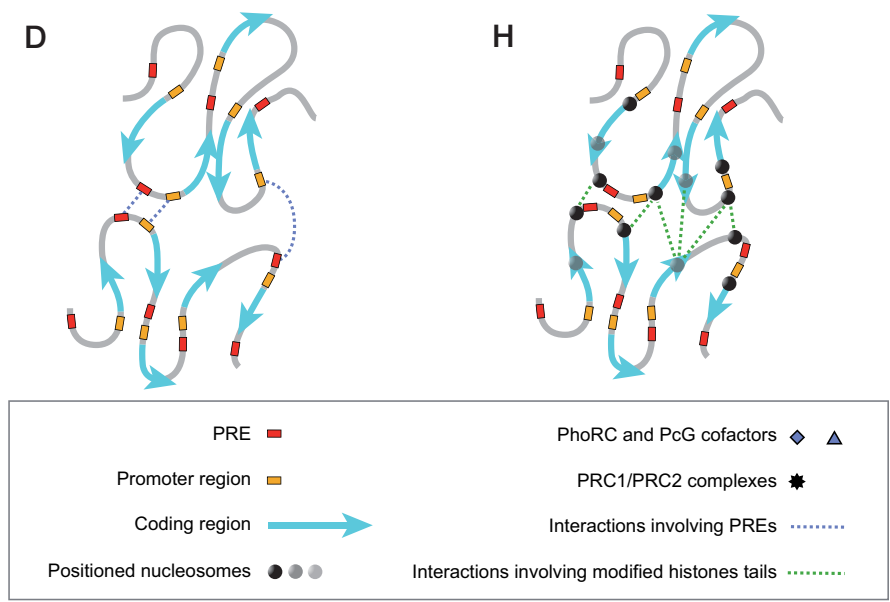

$\mathrm{E}$

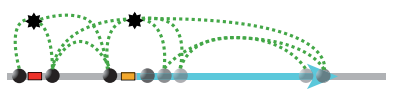

$\mathrm{F}$

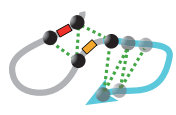

G

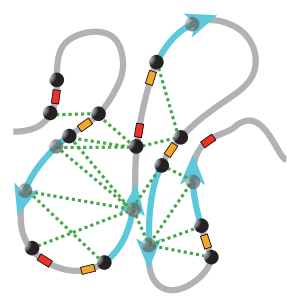

H

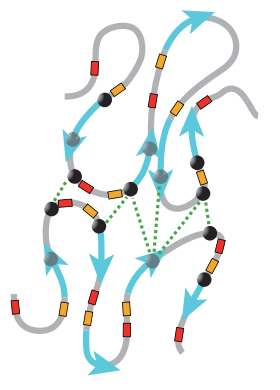

PRC1/PRC2 complexes

Interactions involving PREs

Figure 1. Anchors of chromatin-chromatin interactions. $(A-D)$ Interactions between regulatory DNA elements can be maintained by mechanisms involving proteins such as transcription factors or Polycomb group (PcG) proteins (PhoRC, PRC1, and PRC2), influencing the shape of chromosomes. $(A, B)$ At the level of a single gene, PcG proteins mediate such interactions between PREs and promoter regions. Several neighboring genes can adopt complex 3D conformations $(C)$, forming "chromatin hubs," where promoters, regulatory elements, and transcription factors tend to interact together, whereas intervening DNA sequences form chromatin loops. (D) At megabase scales, specific inter- and intrachromosomal interactions involving similar elements may also occur. It should be noted that, although the $3 \mathrm{C}$ technologies can detect multiple chromatin loops at specific loci, it cannot be resolved whether these contacts occur consecutively or simultaneously. Thus, "chromatin hubs" are averaged 3D chromatin models. $(E-H)$ Nucleosome arrangements may also influence chromosome folding. Nucleosomes are spread all along the chromatin fiber, and nucleosome contacts may lead to the general pattern of interaction frequencies gradually decreasing with distance. However, they may also participate in the formation of specific contacts. Indeed, nucleosomes tend to be positioned relative to sequence elements such as transcription start sites, $3^{\prime}$ ends, and regulatory regions $(E, F)$, and simulation of oligonucleosome chromatin fragments have shown that histone octamers may participate in networks of internucleosomal contacts (Arya and Schlick 2006). Posttranslational modifications of histones may also contribute to these networks by favoring or disfavoring nucleosome interactions. In contrast to tightly anchored chromatin interactions, nucleosomes may provide a substantially broader substrate for interactions that affect chromatin conformation, from local genomic elements to large multigene domains $(G)$, and possibly over large genomic distances $(H)$. Thus, two networks of interactions may contribute synergistically to maintain chromatin conformations - one anchored at small DNA elements, and another one involving nucleosomes. To illustrate this hypothesis, PcG activity relies on specific regulatory sequences bound by specific localized factors $(A-D)$, on deposition of posttranslational modifications of histones over large genomic regions, and on interactions with nucleosomes presenting such modifications. In this case, PcG-nucleosome interactions may provide self-reinforcement mechanisms for maintenance of repressive histone marks and of chromatin conformation $(E, F)$.

core promoters, and the $3^{\prime}$ ends of genes (Schuettengruber et al. 2009). Remarkably, all the major PcG-bound elements at the bithorax locus physically associate at a distance following PcG-dependent silencing, creating a repressive hub-like structure. In embryonic tissues where one of the BX-C genes is active, this gene loops out of the hub, indicating that this higher-order chromatin structure might play a functional role in repression. Thus, there is a good correlation between $\mathrm{PcG}$ binding and repressive chromatin loop formation. Outside of the H3K27me3 BX$\mathrm{C}$ domain, interactions are completely lost, indicating that this folded chromatin may help to isolate genomic regions 
from unrelated neighboring chromatin and might aid the creation and/or maintenance of the $\mathrm{H} 3 \mathrm{~K} 27$ me 3 repressive domain. The repressive hub-like structures were found conserved in all four mammalian Hox clusters (Ferraiuolo et al. 2010). Although the PcG protein EZH2 was found to be involved in looping, the investigators noticed by computational analysis a good correspondence between anchor sites and CTCF binding sites, making the insulator protein a good candidate mediating DNA loops at silent mammalian Hox clusters. In the human GATA-4 gene locus, PcG-bound regions enriched for H3K27me3 physically interact to form chromatin loops in order to maintain the gene in a silent but poised state in undifferentiated embryonic stem-like cells (Tiwari et al. 2008b). Following cell differentiation, GATA-4 expression is accompanied by a complete loss of these chromatin loops together with the loss of PcG proteins and repressive chromatin marks. However, in colon cancer cells, the chromatin loops occur at a higher frequency, dependent on DNA methylation and resulting in irreversible, strong repression. In mammals, methyl-DNA-binding proteins at $\mathrm{CpG}$ islands may thus reinforce the function of these PcG-dependent chromatin hubs (Tiwari et al. 2008b).

\section{Long-Range Intrachromosomal Interactions}

Long-range associations monitored by RNA FISH and $3 \mathrm{C}$ have been described between active genes located in a $40-\mathrm{Mb}$ region on the same chromosome, which often colocalize to shared sites of ongoing transcription (Osborne et al. 2004). The recent development of 4C (3C-based techniques to detect multiple genomic sequences interacting with a specific "bait" of interest) have largely confirmed the existence of long-range intrachromosomal contacts, adding another degree of complexity to chromatin organization (for review, see deLaat 2007; Ohlsson and Göndor 2007).

A common theme of these $4 \mathrm{C}$ analyses is that intrachromosomal interaction frequencies are strongly dependent on genomic distance. Indeed, adjacent sequences on the linear chromosome template were found to be highly overrepresented (Lomvardas et al. 2006; Simonis et al. 2006; Wurtele and Chartrand 2006; Zhao et al. 2006). For exam$\mathrm{ple}$, the strongest $4 \mathrm{C}$ signals mapped within a 5 - to $10-\mathrm{Mb}$ region centered around the $\beta$-globin bait (Simonis et al. 2006). The genome-wide scanning of HoxB1-associated loci distinguished three classes of interactions based on their signal strength. The first class was centered at the bait HoxB locus, covering $\sim 110 \mathrm{~kb}$. The second class extended to a domain of $\sim 800 \mathrm{~kb}$, and the third class represented the less dense and more distal intrachromosomal contacts (Wurtele and Chartrand 2006). Related to the fact that sequence proximity strongly influences contact probability, the $4 \mathrm{C}$ procedure was recently used to identify complex chromosomal rearrangements (Simonis et al. 2009).

Although it seems logical that interaction frequencies decrease as genomic distances increase, specific longrange intrachromosomal interactions over several tens of megabases are also clearly detected (Simonis et al. 2006; Wurtele and Chartrand 2006; Zhao et al. 2006; Schoenfelder et al. 2010). 4C analysis revealed that each locus tested so far preferentially contacts multiple genomic regions, and that these interactions might be the consequence of general folding patterns of chromosomes inside the nucleus. For example, the interacting partners of the active mouse $\beta$-globin are grouped within $70 \mathrm{Mb}$ centered around the globin locus and biased toward the telomere of its acrocentric chromosome, whereas the interactors of the repressed $\beta$-globin genes preferentially tend to be distributed more toward the centromere (Simonis et al. 2006). An asymmetrical distribution of the interactors was also noted with respect to the H19 ICR bait (Zhao et al. 2006). It is important to note here that $4 \mathrm{C}$ can only yield an average conformation of the chromatin fiber, which is gleaned from many thousands of cell nuclei. In the future, it will be interesting to combine such $4 \mathrm{C}$ analysis and sophisticated FISH techniques such as the color barcode labeling of chromosomes (Lowenstein et al. 2004) to address the cellto-cell differences in chromosome topology and get more insight into developmental and cell-type-specific features of higher-order chromosome architecture.

The $4 \mathrm{C}$ results also converge on the proposal that the genome segregates into nuclear domains specifying transcriptionally active and inactive regions. For example, in fetal liver cells, the active $\beta$-globin locus predominantly contacts other active regions, whereas in brain cells, the inactive $\beta$-globin locus preferentially interacts with other inactive regions (Simonis et al. 2006). When $4 \mathrm{C}$ was applied to $\operatorname{Rad} 23 a$, a housekeeping gene in a gene-dense region, many long-range interactions were found with other active gene clusters, and many of these interactions appeared conserved between different cell types (Simonis et al. 2006). It is attractive to speculate that intrachromosomal interactions might serve to accommodate tissue-specific transcriptional gene networks, where specific $c i$-interactors are regulated by the same set of transcription factors. In the case of the $\beta$-globin interactome, although some hits were erythroid-specific genes, others were not, suggesting that this model may be oversimplified (Simonis et al. 2006; Schoenfelder et al. 2010). However, the interactors with the H19 ICR were strongly overrepresented in imprinted domains, suggesting an epigenetic function for these interactions (Zhao et al. 2006; Sandhu et al. 2009). Therefore, many of the interactions identified by $4 \mathrm{C}$ technology may be a consequence of the general chromosomal folding pattern, whereas some of these cis long-range interactions might be involved in the modulation of specific epigenetic pathways. In summary, chromatin loops emerge from specific interactions involving activating or repressive chromatin factors (Fig. 1A-D) as well as nonspecific interactions that may involve general chromatin components such as nucleosomes (Fig. $1 \mathrm{E}-\mathrm{H})$, leading to the general pattern of interaction frequencies gradually decreasing with distance and interaction peaks indicative of specific contacts.

\section{Interchromosomal Interactions}

Communication between regulatory elements and genes on separate chromosomes was initially described genetically in the phenomenon of transvection in Drosophila 
(for review, see Duncan 2002). FISH studies have subsequently confirmed the interchromosomal coassociations predicted by transvection effects (Ronshaugen and Levine 2004). Based on FISH and in vivo gene tagging analysis in Drosophila, tissue-specific interchromosomal interactions were reported for transgenic PRE-containing constructs located on different chromosomes (Bantignies et al. 2003; Vazquez et al. 2006; Fedorova et al. 2008). These long-distance nuclear coassociations correlate well with the reinforcement of PcG-mediated silencing. Deletion of the endogenous Fab-7 PRE in the BX-C locus clearly reduced the interchromosomal interaction between the BX$\mathrm{C}$ and transgenic loci, leading to derepression of the transgene. This result suggests a functional link between the genomic interaction and transcriptional regulation. Consistent with a role of $\mathrm{PcG}$ proteins in long-range interactions, the use of a novel combined 3C-ChIP-cloning (6C) assay reveals that the $\mathrm{PcG}$ protein EZH2 is able to bring distant chromatin regions, both intra- and interchromosomally, together in the three-dimensional (3D) space of the mammalian nucleus (Tiwari et al. 2008a).

In vertebrates, chromosomes are able to intermingle (Branco and Pombo 2006), and many genes can leave their chromosome territories during regulation of their expression (for review, see Fraser and Bickmore 2007). Radial gene positioning inside chromosome territories is an important factor related to the frequency of interchromosomal associations. For instance, more interchromosomal interactions were observed for the Rad23a gene-dense region, which resides mostly at the edge of its chromosome territory, as compared to the $\beta$-globin locus, which has been shown to be more internally located respective to its chromosome territory (Simonis et al. 2006). Following differentiation, the mouse Hoxb gene cluster is activated concomitantly with looping out of its chromosome territory (Chambeyron and Bickmore 2004). A consequence of this relocation, as assessed by $4 \mathrm{C}$, is that the "looped out" Hoxb locus can interact more with other chromosomes (Wurtele and Chartrand 2006). Finally, the increased tendency of the H19 ICR locus to loop out during ES cell differentiation leads to a significant loss of intrachromosomal interactions, therefore augmenting the ratio toward interchromosomal contacts (Sandhu et al. 2009).

The idea that specific interchromosomal gene networks might exist was suggested by the fact that H19 ICR 4C partners were overrepresented in imprinted domains (Zhao et al. 2006; Sandhu et al. 2009). Thus, epigenetic features associated with imprinted domains may be recognized by the H19 ICR in the nuclear space. A very recent study extended this notion of spatial gene networks further. The investigators developed a new genome-wide adaptation of the $3 \mathrm{C}$ combined with $\mathrm{ChIP}$, named $\mathrm{e} 4 \mathrm{C}$, for the analysis of gene coassociations in transcription factories with the mouse $\alpha$-globin and $\beta$-globin genes (Schoenfelder et al. 2010). For both genes, a large majority of the interacting domains, defined as significantly clustered regions of e4C hits of $\sim 100 \mathrm{~kb}$, were located on different chromosomes (88\% and $93 \%$, for $\beta$-globin and $\alpha$-globin, respectively), and many of these interchromosomal interactions were confirmed by FISH analysis. Among the globin-interact- ing loci, genes regulated by the erythroid transcription factor Klfl were overrepresented, and most interestingly, it was shown that Klf1-regulated genes preferentially clustered at a limited number of transcription factories enriched for Klfl protein. This is consistent with the finding that plasmid reporter constructs with similar promoters have a greater tendency to cluster at shared transcription factories than constructs with heterologous promoters $(\mathrm{Xu}$ and Cook 2008). e4C revealed more trans-interactions than cis, which contrasts with the prevalence of intrachromosomal contacts observed with other 4C approaches. As mentioned by the investigators, the reasons for this discrepancy may be explained by the sensitivity and specificity of the e4C technique (Schoenfelder et al. 2010). One might consider that the repertoire of interchromosomal interactions may be larger than the intrachromosomal one, but this does not necessarily mean that these interactions are stronger or more frequent. Related to this point, their RNA FISH analysis confirms that genes in cis generally colocalize more frequently than genes in trans.

The functional significance of such interchromosomal interactions is a topic of hot debate. Today, most examples described are correlative. For example, long-range association of transcription factor-binding sites or coregulated genes correlate with an increased probability of transcriptional activity of the clustered alleles (Apostolou and Thanos 2008; Schoenfelder et al. 2010). However, proving that such associations are functionally relevant is technically difficult. The effect of removing candidate proteins that mediate these interactions can be difficult to interpret, because these factors can be directly involved in the transcriptional regulation of the locus or can lead to pleiotropic indirect effects. Therefore, mutation/deletion of candidate binding sites or of genomic elements is preferable to assess the functional aspects of genomic interactions. For instance, in the examples of the $T_{H} 2 \mathrm{LCR}$ and the H19 ICR (Spilianakis et al. 2005; Ling et al. 2006; Zhao et al. 2006), deletion or mutation of genetic elements on one chromosome affected the expression of interacting genes in trans, suggesting a functional significance of these interchromosomal interactions. A counterexample concerns the $\mathrm{H}$ enhancer, which engages in cis and in trans interactions with odorant genes (Lomvardas et al. 2006). Its deletion abolished expression of the cis-flanking odorant receptor genes; however, no demonstrable effects were detected on odorant receptor gene expression in trans (Fuss et al. 2007; Nishizumi et al. 2007). Similarly, it was demonstrated that the human $\alpha$-globin and $\beta$-globin gene loci are frequently associated when active in erythroid cells (Brown et al. 2006), but a complete deletion of the $\alpha$-globin locus does not affect expression of the $\beta$-globin locus (Weatherall and Clegg 2001).

\section{Genome Interactomes}

4C studies require the choice of a set of bait loci. To gain more insight into the large-scale nuclear organization of the genome, three recent studies report a comprehensive mapping of long-range interactions, both in human and yeast nuclei (Lieberman-Aiden et al. 2009; Rodley et al. 2009; 
Duan et al. 2010). Here, the investigators used an unbiased approach to map all possible intra- and interchromosomal interactions in a given cell population. These genome-wide interactome studies recapitulate known features of genome organization, and also identify new important features.

As stressed by $4 \mathrm{C}$ analyses, interchromosomal interactions tend to be less frequent than intrachromosomal interactions in both yeast and human (Lieberman-Aiden et al. 2009; Duan et al. 2010). In human cells, small generich chromosomes interact frequently with each other compared to larger chromosomes, but interact poorly with the small gene-poor chromosome 18 (Lieberman-Aiden et al. 2009). This is consistent with FISH studies showing that gene-dense chromosomes are frequently juxtaposed at the center of the nucleus (Boyle et al. 2001; Tanabe et al. 2002a; Bolzer et al. 2005), and that chromosome 18 is located more toward the nuclear periphery (Croft et al. 1999). Moreover, interaction frequencies between DNA fragments separated by $200 \mathrm{Mb}$ on the same chromosome are still higher than interaction frequencies between these fragments and other chromosomes. These results coincide well with the existence of chromosome territories. In yeast, although they are generally considered not to contain classical chromosome territories, smaller chromosomes are also involved in more interchromosomal interactions than larger ones (Duan et al. 2010). This property can be explained by the Rabl configuration of yeast chromosomes, whereby small chromosome arms are crowded at the centromere pole to make more frequent contacts with other chromosomes.

Although it was observed that genomic distance greatly influences interaction frequencies, variations of intra- and interchromosomal interaction frequencies at the megabase scale reveal the tendency of genome sequences to form two distinct compartments in human nuclei, arbitrarily named A and B (Lieberman-Aiden et al. 2009). Compartment A correlates strongly with higher gene density, higher expression, and higher DNase I accessibility, whereas compartment B corresponds to gene-poor regions and has tighter intrachromosomal interactions, a property suggestive of compaction (Dekker 2008). Interestingly, this dual compartmentalization was conserved in cancer cells, which possess a highly rearranged genome. This demonstrates that open and closed chromatin domains throughout the genome occupy different spatial compartments in the nucleus. At the subchromosomal level, this spatial separation was also visualized using FISH probes that differentially labeled several gene-poor and gene-rich regions distributed in an alternate fashion on the linear template of a genomic region (Shopland et al. 2006).

The work described by Lieberman-Aiden et al. (2009) is also interesting in reference to earlier comparisons of transcriptome maps and distributions of coding regions, which revealed that the linear human chromosomes are comprised of gene-rich regions, called RIDGES, and gene-poor regions, named anti-RIDGES (Caron et al. 2001; Versteeg et al. 2003; Gierman et al. 2007). RIDGES and anti-RIDGES constitute domains of broad transcriptional regulation regardless of the influence of specific transcription factors. The observation of these domains in microscopy shows lit- tle intermingling between chromatin from different compartments of the same chromosome, suggesting that genepoor and gene-dense regions are spatially partitioned in the cell nucleus (Goetze et al. 2007), in perfect agreement with the latter interactome results. Moreover, in six different human cell lines, RIDGES form structures less condensed, more irregularly shaped, and located farther from the nuclear periphery than anti-RIDGES, demonstrating that gene density, regardless of cell type, acts as an important factor in the 3D compartmentalization of chromosomes, providing two distinct and morphologically different environments (Goetze et al. 2007).

Although 3C-based approaches and its derivatives clearly give evidence for specific arrangements of the chromatin fiber, which contribute to the functional organization of the genome, the mechanisms controlling the folding of the chromatin inside the cell nucleus remain largely unknown. In the second part of this chapter, we focus on the mechanisms that may be responsible for the nonrandom folding of chromatin fibers and nuclear organization.

\section{PRINCIPLES OF NUCLEAR ORGANIZATION}

The distribution of nuclear proteins is not uniform, and they often accumulate in small nuclear subvolumes described as nuclear bodies in optical microscopy (Fig. 2). Although they have no membrane, these structures could serve as platforms on which chromatin specifically binds, and this might account for their nonrandom nuclear organization. Numerous nuclear bodies and compartments have been previously described (for review, see Spector 2001). In order to illustrate the principles accounting for the formation of nuclear bodies and nonrandom 3D chromatin organization, we only focus on a few nuclear bodies.

\section{Insulator and PcG bodies}

Insulator proteins coalesce into foci in the nuclei of diploid cells and may bring distant insulator sites into physical proximity and establish isolated chromatin domains (Gerasimova et al. 2000). The clustering of insulator proteins may rely on the self-interacting properties of the $\mathrm{BTB} / \mathrm{POZ}$ domain, which is present in two proteins required for insulator function: Mod(mdg4) and CP190 (Pai et al. 2004). The nuclear clustering of insulator complexes is lost in the absence of $\operatorname{Mod}(\operatorname{mdg} 4)$, and insulator activity is compromised (Capelson and Corces 2005). Nevertheless, the functional relevance of insulator bodies has been recently challenged because a mutant $\operatorname{Mod}(\operatorname{mdg} 4)$ protein devoid of the Q-rich domain binds to correct insulator sites on the chromosome and is still functionally active but does not accumulate in insulator bodies. In contrast, a C-truncated $\operatorname{Mod}(\operatorname{mdg} 4)$ mutant is functionally inactive and does not associate with the genuine insulators, although it accumulates in insulator bodies (Golovnin et al. 2008). Although these bodies clearly contain both insulator proteins and a chromatin insulator element, whether insulator activity requires insulator bodies to be fully functional is still controversial. 


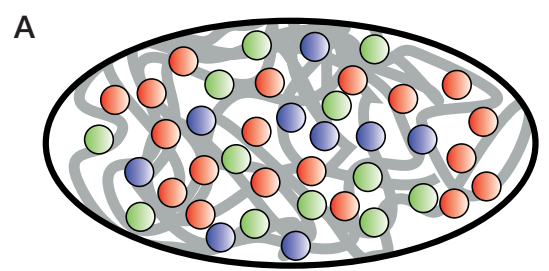

B

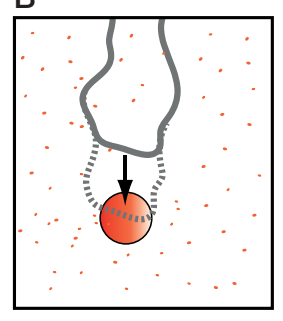

$\mathrm{C}$

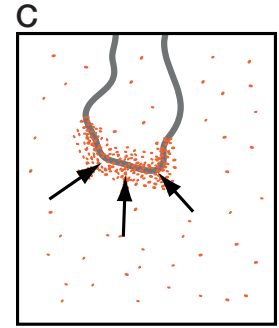

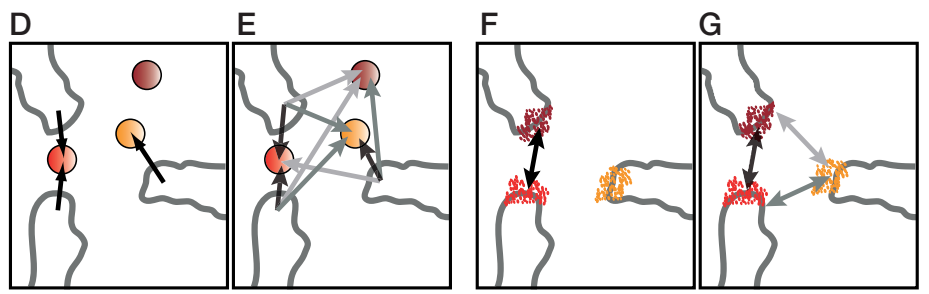

Figure 2. Formation of nuclear bodies. (A) Nuclear localization of nuclear bodies (insulator bodies: blue; PcG bodies: green; transcription factories: red) compared to chromatin fiber (gray). $(B, C)$ Models for formation of a single nuclear body: Proteins composing each nuclear body (red dots) may form a distinct preexisting compartment (red ball) to which chromatin fibers move to be processed $(B)$. Alternatively, proteins (red dots) directly bind to specific binding sites on the chromatin fiber, resulting in the formation of a nuclear body $(C)$. Deterministic $(D, F)$ or probabilistic $(E, G)$ models for localization of chromatin fibers to nuclear bodies. If motion and association of chromatin fiber to specific nuclear bodies are controlled by determinist mechanisms, a specific locus will always move to the same kind of nuclear bodies $(D)$. This would restrict the possibilities of chromosome interactions and imply that strong specific mechanisms such as actindependent directional motion control the positioning of chromatin loci. In contrast, probabilistic association of chromatin fiber with nuclear bodies $(E)$ is consistent with the constrained diffusion of chromatin and the probabilistic nature of chromosome interactions.

Similar localization of chromosomal loci at nuclear bodies is also reported with gene silencing depending on PcG proteins in Drosophila. PcG proteins accumulate in nuclear PcG bodies, which also contain repressed PcG target genes (Buchenau et al. 1998; Grimaud et al. 2006; Lanzuolo et al. 2007). For instance, Fab-7, a PRE controlling the expression of the gene $A b d-B$, is found within Polycomb bodies in the head of Drosophila embryos, where $A b d-B$ is repressed, whereas in the posterior part, where $A b d-B$ is expressed, Fab-7 is located outside of PC bodies (Lanzuolo et al. 2007). However, the functional relevance of these nuclear bodies remains to be determined, and the structural mechanisms controlling their formation are still enigmatic. In Drosophila tissues and in mammalian embryonic stem cells, PcG proteins exchange rapidly between PC bodies and the nucleoplasm (Ficz et al. 2005; Ren et al. 2008). PREs have also been shown to contact distal loci on the same or other chromosomes, and frequent interaction depends on PcG proteins (Bantignies et al. 2003; Vazquez et al. 2006) as well as genes involved in the RNAi pathway (Grimaud et al. 2006). Therefore, targeted genes also appear to move inside of the cell nucleus to come into close proximity in a single PcG body, demonstrating that their formation does not only rely on protein kinetics.

\section{Nuclear Compartments and Protein Kinetics}

The kinetics of GFP-tagged nuclear proteins demonstrates that the nuclear compartments observed in fixed cells are structures in dynamic equilibrium in living cells. Nuclear proteins diffuse relatively freely in the nucleoplasm until they interact within their compartments, where they transiently bind (Misteli 2007). Because the residence times of histones are much longer than most other proteins, chromatin appears to be a relatively stable structure on which proteins may dynamically interact to form functional nuclear compartments. However, the presence of structures composed of multiple proteins also implies that a specific set of nuclear proteins interacts together to form nuclear bodies. In this regard, a recent work regarding Cajal Bodies (CB), major nuclear bodies involved in the biogenesis and recycling of several classes of small nuclear ribonucleoproteins, provides fundamental insights regarding the formation of nuclear bodies. The immobilization of fusion proteins GFP-LacI in a HeLa cell line having 256 repeats of the Lac operator stably integrated is sufficient for the formation of CB. The percentage of cells exhibiting formation of $\mathrm{CB}$ depends on the fusion proteins immobilized, and no $\mathrm{CB}$ forms when proteins other than $\mathrm{CB}$ components 
are immobilized (Kaiser et al. 2008). Therefore, CB formation exhibits hallmarks of a self-organizing structure, and immobilization of $\mathrm{CB}$ components on chromatin results in an artificial nucleation site. However, it remains to be determined if endogenous nucleation sites occur spontaneously within nucleoplasm or require a chromatin or RNA template for CB formation.

Another recent study on DNA repair complexes shows that individual nucleotide excision DNA-repair machinery components exchange within tens of seconds between the repair complexes and the nucleoplasm. The investigators propose a predictive kinetic model whereby stochastic, reversible protein-binding events and progressive enzymatic modifications of the chromatin substrate organize DNA repair (Luijsterburg et al. 2010). A similar model has been suggested for the assembly of RNA polymerase I (Pol I) subunits on endogenous ribosomal RNA genes. Pol I subunits rapidly exchange at the promoter and stably associate with chromatin only during elongation. The kinetics of Pol I subunits suggests that the polymerase machinery assembles at the promoter via a stepwise process occurring by stochastic collisions of subunits (Dundr et al. 2002). This work indicates that the nuclear position of nucleoli relies on the localization of ribosomal DNA (rDNA) on which the Pol I machinery assembles. Consistently, ectopic expression of ribosomal genes on plasmids leads to the biogenesis of micronucleoli (Karpen et al. 1988), and the reforming nucleolus at the telophase $/ \mathrm{G}_{1}$ boundary is nucleated around the reactivated ribosomal genes (Hernandez-Verdun et al. 2002). These examples strongly suggest that the machinery for chromatin-related biological functions, such as DNA repair and Pol I transcription, nucleate on specific chromatin-binding sites to form the nuclear bodies in which these processes occur.

The transcription of mRNA by the Pol II machinery has been extensively studied (Becker et al. 2002; Kimura et al. 2002; Boireau et al. 2007; Darzacq et al. 2007; Yao et al. 2007), and similar to Pol I and DNA repair machineries, Pol II also exchanges between transcription sites and nucleoplasm. In the cell nucleus, Pol II transcription occurs in a distinct punctuate spatial pattern, and the transcriptional activity at individual gene alleles correlates with their positioning within transcription factories, whereas identical inactive alleles do not locate in factories (Osborne et al. 2004). For example, before activation, the majority of immediate-early gene alleles are not associated with transcription factories, whereas following induction, these genes rapidly relocate to preformed transcription factories (Osborne et al. 2007). During inhibition of elongation, distal active genes remain associated inside Pol II foci, whereas inhibition of transcription initiation induces the dissociation of active genes, which relocate outside Pol II foci (Mitchell and Fraser 2008). Therefore, during initiation of transcription, coregulated genes may locate to the same transcription factories and remain associated during their entire elongation, which implies that Pol II foci may exist as independent nuclear subcompartments and that genes may move toward them to be transcribed (Mitchell and Fraser 2008). Accordingly, recent studies identified long-range directional motion of specific loci occurring after their transcriptional induction. An interphase chromosome site located at the nuclear periphery undergoes directional motion toward the interior of the cell nucleus 1-2 $\mathrm{h}$ after its induction, and specific actin or nuclear myosin I mutants inhibit this migration (Chuang et al. 2006). Similar long-range directional motion depending on $\beta$-actin also occurs after transcriptional activation of U2 genes, which are recruited toward a relatively stably positioned Cajal Body (Dundr et al. 2007). Although these two examples provide evidence for long-range directional motion (Fig. 2), implying specific biological mechanisms that are able to target loci to nuclear subcompartments, they occur after a delay that is long compared to transcription induction, and this might not apply to all transcribed genes.

\section{Intranuclear Movement of Chromatin and Nuclear Bodies}

In contrast to proteins that diffuse within the entire nuclear volume, the motion of chromosome loci generally diffuses within a subvolume corresponding approximately to the chromosome territory (Marshall et al. 1997; Heun et al. 2001; Vazquez et al. 2001). Moreover, the movement of chromatin loci depends on their nuclear localization because loci closer to the nucleoli and the nuclear periphery are less mobile than other loci (Chubb et al. 2002). The constrained diffusion of chromatin loci indicates that they can move within a nuclear subvolume without any specific mechanisms, but that some factors such as attachment to a putative nuclear scaffold structure or complex chromatin folding prevent them from freely diffusing in the entire nuclear volume. Therefore, they can passively reach any nuclear bodies located within their volume of confinement, whereas larger movements would rely on specific mechanisms such as directional motion that could depend on actin and myosin (Chuang et al. 2006; Dundr et al. 2007). Mobile chromatin in cell nuclei composed of relatively immobile nuclear bodies would strongly suggest that the latter organize the nuclear volume because immobile structures could constitute platforms used to organize the chromatin fiber. However, the mobility of nuclear bodies is also clearly established. For example, the motion of Cajal Bodies has been described by anomalous diffusion, alternating between association with chromatin and diffusion within the interchromatin space (Platani et al. 2002). The mobility of nuclear bodies might reflect the dynamics and accessibility of the chromatin environment because the motion of inactive protein crystals $(\mathrm{Mx} 1)$ is similar to the one of promyelocytic leukemia (PML) or Cajal Bodies (Gorisch et al. 2004). To specifically address the dynamics of independent Pol II factories on which genes bind to be transcribed, the motion of factories should be compared with that of chromatin.

Visualizing transcription in vivo of inducible transgenic arrays demonstrates that large-scale chromatin decondensation occurs after induction of transcription because a single spot decondenses into a series of collinear spots after induction (Tumbar et al. 1999; Muller et al. 2001; Janicki et al. 2004; Hu et al. 2009). Interestingly, the individual GFP spots comprising each array oscillate independently 
of each other, which demonstrates that transgenic arrays of identical genes do not stably bind to a unique transcription factory, instead suggesting that each site of transcription forms an independent structure (Hu et al. 2009). Moreover, this study demonstrates that gene coregulation does not always induce colocalization because the locus containing these transgenic arrays of identical genes and promoters splits into several substructures after induction of transcription. Similarly, the group of heat shock genes does not cluster into one transcription factory in diploid cells of Drosophila (Yao et al. 2007). One of the transgene arrays in mammalian cells associates with nuclear speckles after induction (Hu et al. 2009); the spatial proximity between some coregulated genes may rely on stochastic clustering of active genes around common nuclear speckles, such as the frequent juxtaposition of active $\alpha$-globin and $\beta$-globin genes (Brown et al. 2006, 2008).

Together, these results suggest that nuclear organization does not arise from a unique mechanism controlling the localization of all individual genes. The fast motion of proteins inside the entire nucleus compared to slower chromatin motion restricted to subnuclear volumes suggest that general nonspecific mechanisms may promote the self-organization of nuclear bodies and a default folding of the chromatin fiber. In addition, specific mechanisms could relocate some chromatin loci to appropriated nuclear bodies, and this could rely on directional motion.

\section{MODELING CHROMATIN LOCALIZATION INSIDE THE CELL NUCLEUS}

To address the influence of nonspecific forces on chromatin fiber folding, several approaches use computer simulations of statistical mechanics models. A recent study indicates that architectural patterns can spontaneously form by collective thermodynamic mechanisms resulting from the physical interaction between soluble binding molecules and chromosomes. In this context, the architectural organization of an interphase chromosome is flexible, because the affinity of soluble mediators and the number and location of their attachment sites along chromosomes regulate thermodynamic switches (Nicodemi and Prisco 2009). Similarly, clustering of active DNA and RNA polymerases into factories to form loops could arise simply because of the nonspecific entropic force of depletion attraction (Marenduzzo et al. 2006). Another thermodynamic study suggests that transcription factors can mediate the physical interactions between genes and induce a microphase separation of their binding sites from the rest of the DNA to form transcription foci. Therefore, the clustering of binding sites along the DNA and their eventual periodic location would strongly favor their gathering within the nuclear volume, and different families of genes bound by different transcription factors would form distinct transcription foci (Junier et al. 2010). Interestingly, although factories were initially proposed to arise from immobilized polymerases on which DNA is processed (Cook 1999), computer simulation of the architecture of chromatin demonstrates that the formation of transcription factories is not absolutely dependent on preformed protein structures.
At a larger scale, several groups have tested different models of chromatin folding inside the interphase nucleus that can predict the formation of chromosome territories and their previously described radial positioning. By using coarse-grained molecular dynamic simulations, nonspecific interactions that lead to entropic effects such as depletion attraction can explain the localization of nucleoli and chromocenters and their clustering in Arabidopsis thaliana. Moreover, the formation of chromosome territories requires loops, which determine the level of intermingling between chromosomes (de Nooijer et al. 2009). Similarly, the modeling of human chromosome polymers as strings of beads that adopt an ideal random walk also requires loops to form territories. Moreover, nonspecific forces alone can position compact and thick fibers and chromocenters at the nuclear periphery and long flexible polymers to the interior (Cook and Marenduzzo 2009). To explain chromatin folding and particularly the formation of chromosome territories in interphase nuclei, earlier polymer models introduced loops. However, neither the random-walk/giant-loop model, in which 3-Mb loops attached to a random-walk backbone (Sachs et al. 1995), nor the multiloop-subcompartment model composed of rosettes consisting of multiple 120-kb loops (Munkel et al. 1999), could describe the folding of chromatin at all scales. To overcome this problem, a recent study proposed a new model relying on a self-avoiding random-walk folding of the polymer backbone in which random interactions between two monomers form loops. The random loop polymer model fits with a large data set of in situ 3D distances between pairs of FISH probes and presents a simple explanation for the formation of chromosome territories. Moreover, heterogeneity could be introduced along the chromosome fiber, and different subchromosomal domains could be formed by changing the local looping probability (Mateos-Langerak et al. 2009). Because a random position of loops seems to provide the most accurate description of chromatin folding, this model would suggest that nonspecific mechanisms establish loops along the chromosome, unless the ensemble of specific interactions along the chromatin fiber leads to a random distribution of loops.

Chromosome territories could also arise because entanglement effects cause sufficiently long chromosomes to remain segregated during interphase. Indeed, models suggest that chromosomes would relax in order of $2000 \mathrm{sec}, \sim 10$ days, and $\sim 250$ days in yeast, Drosophila, and human, respectively (Rosa and Everaers 2008). Fast equilibration of yeast chromosomes explains why there is little apparent territorial organization in yeast nuclei, whereas the much longer Drosophila and human chromosomes remain confined to distinct territories (Rosa and Everaers 2008). This model implies that DNA topoisomerase II does not affect chromatin fibers during chromosome decondensation, because the activity of this enzyme would make the chromatin fiber permeable and decrease entanglement effects. Another study analyzing the radial positioning of freely jointed polygonal chains reported that the center of a sphere is highly crowded with many permeable chains being topologically linked, whereas the nonpermeable 
chains fill the space more uniformly and show strongly reduced intermingling (Dorier and Stasiak 2009). A minimal polymer model of decondensing chromosomes obeying entanglement constraints was able to predict the FISH data for mean-square spatial distances (Rosa and Everaers 2008). However, the $3 \mathrm{C}$ data that rely on interaction frequencies at short genomic lengths seem to suggest a much softer fiber than the one derived from FISH data. Simulations of topologically confined model chromosomes require a small concentration of curvature defects (kinks) along the chromatin fiber in order to be in quantitative agreement with interaction frequencies extracted from the recent experimental $3 \mathrm{C}$ data for human chromosomes (Rosa et al. 2010). These models suggest that local chromatin folding is not correctly predicted with simple polymer models and requires additional forces such as kinks or loops to match experimental data. The linear distributions of some proteins and chromatin marks along the chromosomes form local domains (de Wit and van Steensel 2009), and it would be interesting to address the consequence of these domains on local folding or kinking of the chromatin fiber. At larger scales, the activity of topoisomerase II during chromosome decondensation seems to control the level of intermingling between two chromosome territories, and this part of the model can be experimentally tested.

Recent work comparing experimental results with predictions derived from models of chromatin folding suggests that interphase chromatin forms fractal structures. An earlier model proposed that interphase DNA can self-organize into a long-lived, nonequilibrium conformation described as a fractal globule composed of unentangled polymers that crumple into a series of small globules in a beads-on-astring configuration (Grosberg et al. 1993). The recent map of human genome contacts obtained by a technique called $\mathrm{Hi}-\mathrm{C}$ at a resolution of $1 \mathrm{Mb}$ fits with the fractal globule model (Lieberman-Aiden et al. 2009). Moreover, by probing the diffusive behavior of inert fluorescent tracers in the nucleus of living cells, dense nuclear compartments exhibit volume exclusion and diffusive hindrance (Bancaud et al. 2009). A fractal model of chromatin organization correctly describes this kinetics and explains why the dynamics of soluble nuclear proteins does not depend on their size. Furthermore, this study indicates that the fractal architecture of euchromatin and heterochromatin differs and suggests that protein binding to specific targets differs in the two compartments (Bancaud et al. 2009).

These studies tried to explain the folding of chromatin fibers into the nonrandomly organized cell nucleus. However, the functional relevance of such organization, particularly in terms of the regulation of gene expression, is difficult to address. By assuming that a full understanding of nuclear organization necessitates the view that the nucleus is a dynamic system, a recent study demonstrated that the networks of coregulated gene expression and chromosomal association in prometaphase rosettes are mutually related during differentiation (Rajapakse et al. 2009). Coregulated genes during differentiation have a significant tendency to be closely distributed along chromosomes, and the association of homologous chromosomes during prometaphase rosettes depends on the number of coregulated genes they possess. Interestingly, the change of chromosome association networks observed in prometaphase rosettes during differentiation is related to the coregulated gene expression network, resulting in self-organization of lineage-specific chromosomal topologies (Rajapakse et al. 2009).

\section{CONCLUSION}

The unraveling of 3D genome organization has become an exciting field in biology. Particularly, the emergence of 3C-based technologies has largely confirmed the nonrandom organization of chromosomes inside the nucleus. The genome may be organized as a complex 3D network that is determined by physical interactions between genes and regulatory elements. It is likely that the nucleus is predominantly governed by self-organizing principles, such that these chromosomal interactions might be a combination of probabilistic and functional, specific intrachromosomal and interchromosomal associations. To gain further insights into chromatin topology and the functional significance of these chromosomal interactions, much work needs to be done to develop technologies that enable their detection at high resolution in single cells.

Importantly, computational modeling approaches have recently merged with these experimental approaches. Great progress has been made in polymer models that can now explain chromosome territories, and nonspecific forces have been shown to influence the radial positioning of chromatin fibers and perhaps play a crucial role in the formation of nuclear bodies. The exploration of physical mechanisms regulating nuclear architecture and chromatin folding improves our understanding of the principles governing the function of this highly organized organelle.

Rapid technological developments together with computational modeling are beginning to build a detailed 3D picture of genome organization. How such ordering can be achieved and what the functional consequences are for genome regulation are important questions that we must now address.

\section{ACKNOWLEDGMENTS}

We thank Cyril Sarrauste de Menthière for figure artwork and Thomas Sexton for critical reading of the manuscript. T.C., F.B., and G.C. are supported by the CNRS. B.L. is supported by the Ministère de l'Enseignement Supérieur. G.C.'s research was supported by grants of the European Research Council (ERC-2008-AdG No 232947), of the CNRS, the European Union FP6 (Network of Excellence the Epigenome), by the Agence Nationale de la Recherche, by the Association pour la Recherche sur le Cancer, and by the Ministère de l'Enseignement Supérieur.

\section{REFERENCES}

Apostolou E, Thanos D. 2008. Virus infection induces NF-אB-dependent interchromosomal associations mediating monoallelic IFN- $\beta$ gene expression. Cell 134: 85-96.

Arya G, Schlick T. 2006. Role of histone tails in chromatin folding revealed by a mesoscopic oligonucleosome model. Proc Natl Acad Sci 103: 16236-16241. 
Bancaud A, Huet S, Daigle N, Mozziconacci J, Beaudouin J, Ellenberg J. 2009. Molecular crowding affects diffusion and binding of nuclear proteins in heterochromatin and reveals the fractal organization of chromatin. EMBO J 28: 3785-3798.

Banerji J, Rusconi S, Schaffner W. 1981. Expression of a $\beta$-globin gene is enhanced by remote SV40 DNA sequences. Cell 27: 299-308.

Bantignies F, Grimaud C, Lavrov S, Gabut M, Cavalli G. 2003. Inheritance of Polycomb-dependent chromosomal interactions in Drosophila. Genes Dev 17: 2406-2420.

Becker M, Baumann C, John S, Walker DA, Vigneron M, McNally JG, Hager GL. 2002. Dynamic behavior of transcription factors on a natural promoter in living cells. EMBO Rep 3: 1188-1194.

Boireau S, Maiuri P, Basyuk E, de la Mata M, Knezevich A, Pradet-Balade B, Backer V, Kornblihtt A, Marcello A, Bertrand E. 2007. The transcriptional cycle of HIV-1 in real-time and live cells. J Cell Biol 179: 291-304.

Bolzer A, Kreth G, Solovei I, Koehler D, Saracoglu K, Fauth C, Muller S, Eils R, Cremer C, Speicher MR, et al. 2005. Threedimensional maps of all chromosomes in human male fibroblast nuclei and prometaphase rosettes. PLoS Biol 3: e157. doi: 10.1371/journal.pbio.0030157.

Boyle S, Gilchrist S, Bridger JM, Mahy NL, Ellis JA, Bickmore WA. 2001. The spatial organization of human chromosomes within the nuclei of normal and emerin-mutant cells. Hum Mol Genet 10: 211-219.

Branco MR, Pombo A. 2006. Intermingling of chromosome territories in interphase suggests role in translocations and transcription-dependent associations. PLoS Biol 4: e138. doi: 10.1371/ journal.pbio.0040138

Brown JM, Leach J, Reittie JE, Atzberger A, Lee-Prudhoe J, Wood WG, Higgs DR, Iborra FJ, Buckle VJ. 2006. Coregulated human globin genes are frequently in spatial proximity when active. $J$ Cell Biol 172: 177-187.

Brown JM, Green J, das Neves RP, Wallace HA, Smith AJ, Hughes J, Gray N, Taylor S, Wood WG, Higgs DR, et al. 2008. Association between active genes occurs at nuclear speckles and is modulated by chromatin environment. J Cell Biol 182: 1083-1097.

Buchenau P, Hodgson J, Strutt H, Arndt-Jovin DJ. 1998. The distribution of Polycomb-group proteins during cell division and development in Drosophila embryos: Impact on models for silencing. J Cell Biol 141: 469-481.

Capelson M, Corces VG. 2005. The ubiquitin ligase dTopors directs the nuclear organization of a chromatin insulator. Mol Cell 20: $105-116$.

Caron H, van Schaik B, van der Mee M, Baas F, Riggins G, van Sluis P, Hermus MC, van Asperen R, Boon K, Voute PA, et al. 2001. The human transcriptome map: clustering of highly expressed genes in chromosomal domains. Science 291: 1289 1292.

Chambeyron S, Bickmore WA. 2004. Chromatin decondensation and nuclear reorganization of the HoxB locus upon induction of transcription. Genes Dev 18: 1119-1130.

Chuang CH, Carpenter AE, Fuchsova B, Johnson T, de Lanerolle P, Belmont AS. 2006. Long-range directional movement of an interphase chromosome site. Curr Biol 16: 825-831.

Chubb JR, Boyle S, Perry P, Bickmore WA. 2002. Chromatin motion is constrained by association with nuclear compartments in human cells. Curr Biol 12: 439-445.

Cleard F, Moshkin Y, Karch F, Maeda RK. 2006. Probing longdistance regulatory interactions in the Drosophila melanogaster bithorax complex using Dam identification. Nat Genet 38: 931935.

Comet I, Savitskaya E, Schuettengruber B, Negre N, Lavrov S, Parshikov A, Juge F, Gracheva E, Georgiev P, Cavalli G. 2006. PRE-mediated bypass of two $\mathrm{Su}(\mathrm{Hw})$ insulators targets PcG proteins to a downstream promoter. Dev Cell 11: 117-124.

Cook PR. 1999. The organization of replication and transcription. Science 284: 1790-1795.

Cook PR, Marenduzzo D. 2009. Entropic organization of interphase chromosomes. J Cell Biol 186: 825-834.

Cremer T, Kurz A, Zirbel R, Dietzel S, Rinke B, Schrock E, Speicher MR, Mathieu U, Jauch A, Emmerich P, et al. 1993. Role of chromosome territories in the functional compartmentalization of the cell nucleus. Cold Spring Harb Symp Quant Biol 58: 777-792.

Croft JA, Bridger JM, Boyle S, Perry P, Teague P, Bickmore WA. 1999. Differences in the localization and morphology of chromosomes in the human nucleus. J Cell Biol 145: 1119-1131.

Darzacq X, Shav-Tal Y, de Turris V, Brody Y, Shenoy SM, Phair RD, Singer RH. 2007. In vivo dynamics of RNA polymerase II transcription. Nat Struct Mol Biol 14: 796-806.

Dekker J. 2008. Mapping in vivo chromatin interactions in yeast suggests an extended chromatin fiber with regional variation in compaction. J Biol Chem 283: 34532-34540.

Dekker J, Rippe K, Dekker M, Kleckner N. 2002. Capturing chromosome conformation. Science 295: 1306-1311.

de Laat W. 2007. Long-range DNA contacts: Romance in the nucleus? Curr Opin Cell Biol 19: 317-320.

de Nooijer S, Wellink J, Mulder B, Bisseling T. 2009. Non-specific interactions are sufficient to explain the position of heterochromatic chromocenters and nucleoli in interphase nuclei. Nucleic Acids Res 37: 3558-3568.

de Wit E, van Steensel B. 2009. Chromatin domains in higher eukaryotes: Insights from genome-wide mapping studies. Chromosoma 118: $25-36$

Dorier J, Stasiak A. 2009. Topological origins of chromosomal territories. Nucleic Acids Res 37: 6316-6322.

Dostie J, Richmond TA, Arnaout RA, Selzer RR, Lee WL, Honan TA, Rubio ED, Krumm A, Lamb J, Nusbaum C, et al. 2006. Chromosome Conformation Capture Carbon Copy (5C): A massively parallel solution for mapping interactions between genomic elements. Genome Res 16: 1299-1309.

Duan Z, Andronescu M, Schutz K, Mcllwain S, Kim YJ, Lee C, Shendure J, Fields S, Blau CA, Noble WS. 2010. A three-dimensional model of the yeast genome. Nature 465: 363-367.

Duncan IW. 2002. Transvection effects in Drosophila. Annu Rev Genet 36: 521-556.

Dundr M, Hoffmann-Rohrer U, Hu Q, Grummt I, Rothblum LI, Phair RD, Misteli T. 2002. A kinetic framework for a mammalian RNA polymerase in vivo. Science 298: 1623-1626.

Dundr M, Ospina JK, Sung MH, John S, Upender M, Ried T, Hager GL, Matera AG. 2007. Actin-dependent intranuclear repositioning of an active gene locus in vivo. J Cell Biol 179: 1095-1103.

Fedorova E, Sadoni N, Dahlsveen IK, Koch J, Kremmer E, Eick D, Paro R, Zink D. 2008. The nuclear organization of Polycomb/Trithorax group response elements in larval tissues of Drosophila melanogaster. Chromosome Res 16: 649-673.

Ferraiuolo MA, Rousseau M, Miyamoto C, Shenker S, Wang XQ, Nadler M, Blanchette M, Dostie J. 2010. The three-dimensional architecture of Hox cluster silencing. Nucleic Acids Res 38: 7472-7484

Ficz G, Heintzmann R, Arndt-Jovin DJ. 2005. Polycomb group protein complexes exchange rapidly in living Drosophila. Development 132: 3963-3976.

Foster HA, Bridger JM. 2005. The genome and the nucleus: A marriage made by evolution. Genome organisation and nuclear architecture. Chromosoma 114: 212-229.

Foster HA, Abeydeera LR, Griffin DK, Bridger JM. 2005. Nonrandom chromosome positioning in mammalian sperm nuclei, with migration of the sex chromosomes during late spermatogenesis. J Cell Sci 118: 1811-1820.

Fraser P, Bickmore W. 2007. Nuclear organization of the genome and the potential for gene regulation. Nature 447: 413-417.

Fullwood MJ, Liu MH, Pan YF, Liu J, Xu H, Mohamed YB, Orlov YL, Velkov S, Ho A, Mei PH, et al. 2009. An oestrogen-receptor- $\alpha$-bound human chromatin interactome. Nature 462: 58-64.

Fuss SH, Omura M, Mombaerts P. 2007. Local and cis effects of the $\mathrm{H}$ element on expression of odorant receptor genes in mouse. Cell 130: 373-384.

Gerasimova TI, Byrd K, Corces VG. 2000. A chromatin insulator determines the nuclear localization of DNA. Mol Cell 6: 1025 1035 .

Gierman HJ, Indemans MH, Koster J, Goetze S, Seppen J, Geerts D, van Driel R, Versteeg R. 2007. Domain-wide regulation of 
gene expression in the human genome. Genome Res 17: 1286 1295.

Goetze S, Mateos-Langerak J, Gierman HJ, de Leeuw W, Giromus $\mathrm{O}$, Indemans MH, Koster J, Ondrej V, Versteeg R, van Driel R. 2007. The three-dimensional structure of human interphase chromosomes is related to the transcriptome map. Mol Cell Biol 27: 4475-4487.

Golovnin A, Melnikova L, Volkov I, Kostuchenko M, Galkin AV, Georgiev P. 2008. 'Insulator bodies' are aggregates of proteins but not of insulators. EMBO Rep 9: 440-445.

Gorisch SM, Wachsmuth M, Ittrich C, Bacher CP, Rippe K, Lichter P. 2004. Nuclear body movement is determined by chromatin accessibility and dynamics. Proc Natl Acad Sci 101: 1322113226.

Grimaud C, Bantignies F, Pal-Bhadra M, Ghana P, Bhadra U, Cavalli G. 2006. RNAi components are required for nuclear clustering of Polycomb group response elements. Cell 124: 957-971.

Grosberg A, Rabin I, Khavlin S, Nir A. 1993. Self-similarity in the structure of DNA: Why are introns needed? [in Russian]. Biofizika 38: 75-83.

Hadjur S, Williams LM, Ryan NK, Cobb BS, Sexton T, Fraser P, Fisher AG, Merkenschlager M. 2009. Cohesins form chromosomal cis-interactions at the developmentally regulated IFNG locus. Nature 460: 410-413.

Hernandez-Verdun D, Roussel P, Gebrane-Younes J. 2002. Emerging concepts of nucleolar assembly. J Cell Sci 115: 2265-2270.

Heun P, Laroche T, Shimada K, Furrer P, Gasser SM. 2001. Chromosome dynamics in the yeast interphase nucleus. Science 294: 2181-2186.

Hou C, Dale R, Dean A. 2010. Cell type specificity of chromatin organization mediated by CTCF and cohesin. Proc Natl Acad Sci 107: 3651-3656.

Hu Y, Kireev I, Plutz M, Ashourian N, Belmont AS. 2009. Largescale chromatin structure of inducible genes: Transcription on a condensed, linear template. J Cell Biol 185: 87-100.

Janicki SM, Tsukamoto T, Salghetti SE, Tansey WP, Sachidanandam R, Prasanth KV, Ried T, Shav-Tal Y, Bertrand E, Singer $\mathrm{RH}$, et al. 2004. From silencing to gene expression: Real-time analysis in single cells. Cell 116: 683-698.

Junier I, Martin O, Kepes F. 2010. Spatial and topological organization of DNA chains induced by gene co-localization. PLoS Comput Biol 6: e1000678. doi: 10.1371/journal.pcbi.1000678.

Kaiser TE, Intine RV, Dundr M. 2008. De novo formation of a subnuclear body. Science 322: 1713-1717.

Karpen GH, Schaefer JE, Laird CD. 1988. A Drosophila rRNA gene located in euchromatin is active in transcription and nucleolus formation. Genes Dev 2: 1745-1763.

Kimura H, Sugaya K, Cook PR. 2002. The transcription cycle of RNA polymerase II in living cells. $J$ Cell Biol 159: 777-782.

Kosak ST, Scalzo D, Alworth SV, Li F, Palmer S, Enver T, Lee JS, Groudine M. 2007. Coordinate gene regulation during hematopoiesis is related to genomic organization. PLoS Biol 5: e309. doi: 10.1371/journal.pbio.0050309.

Lanzuolo C, Roure V, Dekker J, Bantignies F, Orlando V. 2007. Polycomb response elements mediate the formation of chromosome higher-order structures in the bithorax complex. Nat Cell Biol 9: 1167-1174

Lieberman-Aiden E, van Berkum NL, Williams L, Imakaev M, Ragoczy T, Telling A, Amit I, Lajoie BR, Sabo PJ, Dorschner $\mathrm{MO}$, et al. 2009. Comprehensive mapping of long-range interactions reveals folding principles of the human genome. Science 326: 289-293.

Ling JQ, Li T, Hu JF, Vu TH, Chen HL, Qiu XW, Cherry AM, Hoffman AR. 2006. CTCF mediates interchromosomal colocalization between Igf2/H19 and Wsb1/Nf1. Science 312: 269-272.

Lomvardas S, Barnea G, Pisapia DJ, Mendelsohn M, Kirkland J, Axel R. 2006. Interchromosomal interactions and olfactory receptor choice. Cell 126: 403-413.

Lowenstein MG, Goddard TD, Sedat JW. 2004. Long-range interphase chromosome organization in Drosophila: A study using color barcoded fluorescence in situ hybridization and structural clustering analysis. Mol Biol Cell 15: 5678-5692.

Luijsterburg MS, von Bornstaedt G, Gourdin AM, Politi AZ, Mone
MJ, Warmerdam DO, Goedhart J, Vermeulen W, van Driel R, Hofer T. 2010. Stochastic and reversible assembly of a multiprotein DNA repair complex ensures accurate target site recognition and efficient repair. J Cell Biol 189: 445-463.

Maeda RK, Karch F. 2006. The ABC of the BX-C: The bithorax complex explained. Development 133: 1413-1422.

Marenduzzo D, Micheletti C, Cook PR. 2006. Entropy-driven genome organization. Biophys J 90: 3712-3721.

Marshall WF, Straight A, Marko JF, Swedlow J, Dernburg A, Belmont A, Murray AW, Agard DA, Sedat JW. 1997. Interphase chromosomes undergo constrained diffusional motion in living cells. Curr Biol 7: 930-939.

Mateos-Langerak J, Bohn M, de Leeuw W, Giromus O, Manders EM, Verschure PJ, Indemans MH, Gierman HJ, Heermann DW, van Driel R, et al. 2009. Spatially confined folding of chromatin in the interphase nucleus. Proc Natl Acad Sci 106: 3812-3817.

Meister P, Towbin BD, Pike BL, Ponti A, Gasser SM. 2010. The spatial dynamics of tissue-specific promoters during C. elegans development. Genes Dev 24: 766-782.

Misteli T. 2007. Beyond the sequence: Cellular organization of genome function. Cell 128: 787-800.

Mitchell JA, Fraser P. 2008. Transcription factories are nuclear subcompartments that remain in the absence of transcription. Genes Dev 22: 20-25.

Muller WG, Walker D, Hager GL, McNally JG. 2001. Large-scale chromatin decondensation and recondensation regulated by transcription from a natural promoter. $J$ Cell Biol 154: 33-48.

Munkel C, Eils R, Dietzel S, Zink D, Mehring C, Wedemann G, Cremer T, Langowski J. 1999. Compartmentalization of interphase chromosomes observed in simulation and experiment. $J$ Mol Biol 285: 1053-1065.

Nativio R, Wendt KS, Ito Y, Huddleston JE, Uribe-Lewis S, Woodfine K, Krueger C, Reik W, Peters JM, Murrell A. 2009. Cohe$\sin$ is required for higher-order chromatin conformation at the imprinted IGF2-H19 locus. PLoS Genet 5: e1000739. doi: 10.1371/journal.pgen.1000739.

Nicodemi M, Prisco A. 2009. Thermodynamic pathways to genome spatial organization in the cell nucleus. Biophys $J$ 96: 2168-2177.

Nishizumi H, Kumasaka K, Inoue N, Nakashima A, Sakano H. 2007. Deletion of the core-H region in mice abolishes the expression of three proximal odorant receptor genes in cis. Proc Natl Acad Sci 104: 20067-20072.

Ohlsson R, Göndor A. 2007. The 4C technique: The 'Rosetta stone' for genome biology in 3D? Curr Opin Cell Biol 19: 321-325.

Osborne CS, Chakalova L, Brown KE, Carter D, Horton A, Debrand E, Goyenechea B, Mitchell JA, Lopes S, Reik W, et al. 2004. Active genes dynamically colocalize to shared sites of ongoing transcription. Nat Genet 36: 1065-1071.

Osborne CS, Chakalova L, Mitchell JA, Horton A, Wood AL, Bolland DJ, Corcoran AE, Fraser P. 2007. Myc dynamically and preferentially relocates to a transcription factory occupied by Igh. PLoS Biol 5: e192. doi: 10.1371/journal.pbio.0050192.

Pai CY, Lei EP, Ghosh D, Corces VG. 2004. The centrosomal protein CP190 is a component of the gypsy chromatin insulator. Mol Cell 16: 737-748.

Palstra RJ, Tolhuis B, Splinter E, Nijmeijer R, Grosveld F, de Laat W. 2003. The $\beta$-globin nuclear compartment in development and erythroid differentiation. Nat Genet 35: 190-194.

Palstra RJ, Simonis M, Klous P, Brasset E, Eijkelkamp B, de Laat W. 2008. Maintenance of long-range DNA interactions after inhibition of ongoing RNA polymerase II transcription. PLoS One 3: e1661. doi: 10.1371/journal.pone.0001661.

Phillips JE, Corces VG. 2009. CTCF: Master weaver of the genome. Cell 137: 1194-1211.

Platani M, Goldberg I, Lamond AI, Swedlow JR. 2002. Cajal body dynamics and association with chromatin are ATP-dependent. Nat Cell Biol 4: 502-508.

Postberg J, Alexandrova O, Cremer T, Lipps HJ. 2005. Exploiting nuclear duality of ciliates to analyse topological requirements for DNA replication and transcription. J Cell Sci 118: 39733983.

Rajapakse I, Perlman MD, Scalzo D, Kooperberg C, Groudine M, 
Kosak ST. 2009. The emergence of lineage-specific chromosomal topologies from coordinate gene regulation. Proc Natl Acad Sci 106: 6679-6684.

Ren X, Vincenz C, Kerppola TK. 2008. Changes in the distributions and dynamics of Polycomb repressive complexes during embryonic stem cell differentiation. Mol Cell Biol 28: 28842895.

Rodley CD, Bertels F, Jones B, O’Sullivan JM. 2009. Global identification of yeast chromosome interactions using Genome conformation capture. Fungal Genet Biol 46: 879-886.

Ronshaugen M, Levine M. 2004. Visualization of trans-homolog enhancer-promoter interactions at the Abd-B Hox locus in the Drosophila embryo. Dev Cell 7: 925-932.

Rosa A, Everaers R. 2008. Structure and dynamics of interphase chromosomes. PLoS Comput Biol 4: e1000153. doi: 10.1371/journal.pcbi.1000153.

Rosa A, Becker NB, Everaers R. 2010. Looping probabilities in model interphase chromosomes. Biophys J 98: 2410-2419.

Sachs RK, van den Engh G, Trask B, Yokota H, Hearst JE. 1995. A random-walk/giant-loop model for interphase chromosomes. Proc Natl Acad Sci 92: 2710-2714.

Sandhu KS, Shi C, Sjolinder M, Zhao Z, Gondor A, Liu L, Tiwari VK, Guibert S, Emilsson L, Imreh MP, et al. 2009. Nonallelic transvection of multiple imprinted loci is organized by the H19 imprinting control region during germline development. Genes Dev 23: 2598-2603.

Schoenfelder S, Sexton T, Chakalova L, Cope NF, Horton A, Andrews S, Kurukuti S, Mitchell JA, Umlauf D, Dimitrova DS, et al. 2010. Preferential associations between co-regulated genes reveal a transcriptional interactome in erythroid cells. Nat Genet 42: 53-61.

Schuettengruber B, Ganapathi M, Leblanc B, Portoso M, Jaschek R, Tolhuis B, van Lohuizen M, Tanay A, Cavalli G. 2009. Functional anatomy of polycomb and trithorax chromatin landscapes in Drosophila embryos. PLoS Biol 7: e13. doi: 10.1371/journal. pbio. 1000013.

Sexton T, Bantignies F, Cavalli G. 2009. Genomic interactions: Chromatin loops and gene meeting points in transcriptional regulation. Semin Cell Dev Biol 20: 849-855.

Shopland LS, Lynch CR, Peterson KA, Thornton K, Kepper N, Hase J, Stein S, Vincent S, Molloy KR, Kreth G, et al. 2006. Folding and organization of a contiguous chromosome region according to the gene distribution pattern in primary genomic sequence. J Cell Biol 174: 27-38.

Simonis M, Klous P, Splinter E, Moshkin Y, Willemsen R, de Wit E, van Steensel B, de Laat W. 2006. Nuclear organization of active and inactive chromatin domains uncovered by chromosome conformation capture-on-chip (4C). Nat Genet 38: 1348-1354.

Simonis M, Klous P, Homminga I, Galjaard RJ, Rijkers EJ, Grosveld F, Meijerink JP, de Laat W. 2009. High-resolution identification of balanced and complex chromosomal rearrangements by 4C technology. Nat Methods 6: 837-842.

Solovei I, Kreysing M, Lanctot C, Kosem S, Peichl L, Cremer T, Guck J, Joffe B. 2009. Nuclear architecture of rod photoreceptor cells adapts to vision in mammalian evolution. Cell 137: 356 368.

Spector DL. 2001. Nuclear domains. J Cell Sci 114: 2891-2893.

Spilianakis CG, Lalioti MD, Town T, Lee GR, Flavell RA. 2005. Interchromosomal associations between alternatively expressed loci. Nature 435: 637-645.

Tanabe H, Habermann FA, Solovei I, Cremer M, Cremer T. 2002a. Non-random radial arrangements of interphase chromosome territories: Evolutionary considerations and functional implications. Mutat Res 504: 37-45.

Tanabe H, Muller S, Neusser M, von Hase J, Calcagno E, Cremer M, Solovei I, Cremer C, Cremer T. 2002b. Evolutionary conservation of chromosome territory arrangements in cell nuclei from higher primates. Proc Natl Acad Sci 99: 4424-4429.

Tiwari VK, Cope L, McGarvey KM, Ohm JE, Baylin SB. 2008a. A novel $6 \mathrm{C}$ assay uncovers Polycomb-mediated higher order chromatin conformations. Genome Res 18: 1171-1179.

Tiwari VK, McGarvey KM, Licchesi JD, Ohm JE, Herman JG, Schubeler D, Baylin SB. 2008b. PcG proteins, DNA methylation, and gene repression by chromatin looping. PLoS Biol 6: 2911-2927.

Tolhuis B, Palstra RJ, Splinter E, Grosveld F, de Laat W. 2002. Looping and interaction between hypersensitive sites in the active $\beta$-globin locus. Mol Cell 10: 1453-1465.

Tumbar T, Sudlow G, Belmont AS. 1999. Large-scale chromatin unfolding and remodeling induced by VP16 acidic activation domain. J Cell Biol 145: 1341-1354.

Vazquez J, Belmont AS, Sedat JW. 2001. Multiple regimes of constrained chromosome motion are regulated in the interphase Drosophila nucleus. Curr Biol 11: 1227-1239.

Vazquez J, Muller M, Pirrotta V, Sedat JW. 2006. The Mcp element mediates stable long-range chromosome-chromosome interactions in Drosophila. Mol Biol Cell 17: 2158-2165.

Versteeg R, van Schaik BD, van Batenburg MF, Roos M, Monajemi R, Caron H, Bussemaker HJ, van Kampen AH. 2003. The human transcriptome map reveals extremes in gene density, intron length, GC content, and repeat pattern for domains of highly and weakly expressed genes. Genome Res 13: 1998-2004.

Weatherall DJ, Clegg JB. 2001. The Thalassaemia syndromes. Blackwell, Oxford.

Wurtele H, Chartrand P. 2006. Genome-wide scanning of HoxB1associated loci in mouse ES cells using an open-ended Chromosome Conformation Capture methodology. Chromosome Res 14: 477-495.

Xu M, Cook PR. 2008. Similar active genes cluster in specialized transcription factories. J Cell Biol 181: 615-623.

Yao J, Ardehali MB, Fecko CJ, Webb WW, Lis JT. 2007. Intranuclear distribution and local dynamics of RNA polymerase II during transcription activation. Mol Cell 28: 978-990.

Zhao Z, Tavoosidana G, Sjolinder M, Gondor A, Mariano P, Wang S, Kanduri C, Lezcano M, Sandhu KS, Singh U, et al. 2006. Circular chromosome conformation capture (4C) uncovers extensive networks of epigenetically regulated intra- and interchromosomal interactions. Nat Genet 38: 1341-1347. 


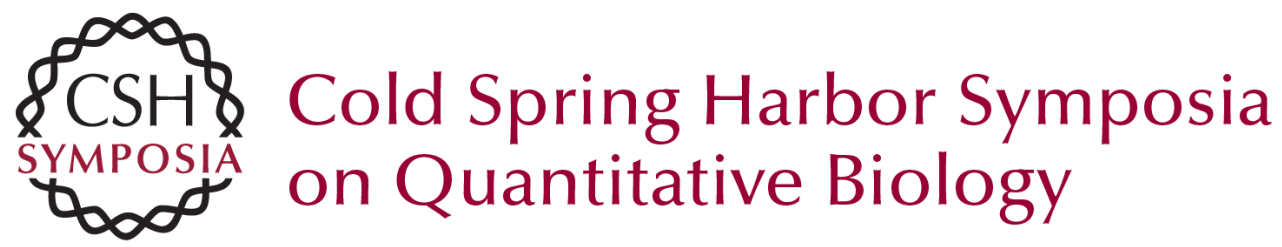

\section{Chromatin Folding: From Linear Chromosomes to the 4D Nucleus}

T. Cheutin, F. Bantignies, B. Leblanc, et al.

Cold Spring Harb Symp Quant Biol 2010 75: 461-473 originally published online March 29, 2011

Access the most recent version at doi:10.1101/sqb.2010.75.029

References This article cites 119 articles, 51 of which can be accessed free at:

http://symposium.cshlp.org/content/75/461.full.html\#ref-list-1

License

Email Alerting Receive free email alerts when new articles cite this article - sign up in the box at the Service top right corner of the article or click here.

To subscribe to Cold Spring Harbor Symposia on Quantitative Biology go to:

http://symposium.cshlp.org/subscriptions 